\title{
Luminescent microporous metal-organic framework with functional Lewis basic sites on the pore surface: quantifiable evaluation of luminescent sensing mechanisms towards $\mathrm{Fe}^{3+}$
}

\author{
Jun-Cheng Jin, ${ }^{\text {ab }}$ Rui-Li Guo, ${ }^{a}$ Wen-Yan Zhang ${ }^{a}$, Chen Jiang, ${ }^{b}$ Yao-Yu Wang ${ }^{\text {a* }}$ \\ ${ }^{a}$ Key Laboratory of Synthetic and Natural Functional Molecule Chemistry of the Ministry of \\ Education, Shaanxi Key Laboratory of Physico-Inorganic Chemistry, College of Chemistry \& \\ Materials Science, Northwest University, Xi'an 710069, China \\ E-mail: wyaoyu@nwu.edu.cn. \\ ${ }^{b}$ Technology Promotion Center of Nano Composite Material Preparation and Application; Anhui \\ Provincial Laboratory of Biomimetic Sensor and Detecting Technology, West Anhui University, \\ Anhui 237012, China
}

\begin{abstract}
*Corresponding authors. Address: Key Laboratory of Synthetic and Natural Functional Molecule Chemistry of the Ministry of Education, Shaanxi Key Laboratory of Physico-Inorganic Chemistry, College of Chemistry \& Materials Science, Northwest University, Xi'an 710069, China. Tel: +86-29-88303798. E-mail addresses: wyaoyu@nwu.edu.cn (Yao-Yu Wang).
\end{abstract}

Keyeords: Microporous MOF, Luminescence sensor, Quantitative evaluation, Quenching mechanisms.

\section{ABSTRACT}

A systematic study has been conducted on a novel luminescent metal-organic framework, $\left\{[\mathrm{Zn}(\text { bpyp })(\mathrm{L}-\mathrm{OH})] \cdot \mathrm{DMF} \cdot 2 \mathrm{H}_{2} \mathrm{O}\right\}_{\mathrm{n}}(\mathbf{1})$, to explore its sensing mechanisms to $\mathrm{Fe}^{3+}$. Structure analyses show that compound $\mathbf{1}$ exist pyridine $\mathrm{N}$ atoms and $-\mathrm{OH}$ groups on the pore surface for specific sensing of metal ions via Lewis acid-base interactions. On this consideration, the quenching mechanisms are studied and the processes are controlled by multiple mechanisms in which dynamic and static mechanisms are calculated, achieving the quantification evaluation of the quenching process. This work not only achieves the quantitative evaluation of the luminescence quenching but also provides certain insights into the quenching process, and the possible mechanisms explored in this work may inspire future research and 
design of target luminescent metal-organic frameworks (LMOFs) with specific functions.

\section{Introduction}

Metal-organic frameworks (MOFs), a kind of porous materials formed by assembly of metal ions with functional organic ligands, have attracted intense research attention due to their versatile structural features and great potentials in a wide range of applications [1-6]. The luminescent MOFs are of great interest as sensing materials, owing to their unique fluorimetric detection methods which possess outstanding sensitivity, rapid detection speed and convenience operation [7-9]. Embedding active functional groups such as $-\mathrm{NH}_{2},-\mathrm{OH},-\mathrm{COOH}$ and pyridyl groups into the organic ligands to construct MOFs can largely improve their ability to recognize and sense neutral and ionic species [10-14]. To date, MOFs have been developed as materials for the sensors in various application fields. For example, Maji’s group has reported a ligand-based luminescent MOF for the selective sensing and removal of metal ions, by exploiting the functional -OH groups on their pore surface [15]. A flexible metal-organic framework turn-off luminescent sensor for the detection of $\mathrm{Fe}^{3+}$ and picric acid has been reported by Zhou and co-workers [16]. Jiang's group reported an amine-functionalized metal-organic framework as a sensing platform for DNA detection [17]. Besides, luminescent MOFs can also function as thermometer by the change of color and intensity [18]. However, though the luminescent MOFs working as functional sensors have covered a wide scope, systemic studies and quantitative evaluations on the sensing mechanisms have been rarely explored.

$\mathrm{Fe}^{3+}$ ions play a crucial role in many biochemical processes, such as the storage and transport of oxygen to tissues and enzymatic reactions of the mitochondrial respiratory chain [19-21]. Either its excess or deficiency is so detrimental that may cause damage to nucleic acids and proteins such as anemia, diabetes, heart failure, liver damage and Parkinson's disease and so on [22-24]. Thus, the monitoring of $\mathrm{Fe}^{3+}$ 
ions in a highly effective and fast method to detect trace amount $\mathrm{Fe}^{3+}$ over other metal ions is of much concern.

We herein report a novel microporous compound, $\left\{[\mathrm{Zn}(\text { bpyp})(\mathrm{L}-\mathrm{OH})] \cdot \mathrm{DMF} \cdot 2 \mathrm{H}_{2} \mathrm{O}\right\}_{\mathrm{n}}$ (1) [bpyp = 2,5-bis(pyrid-4-yl)pyridine, L-OH = 5-hydroxyisophthalic acid, DMF = dimethylformamide], containing uncoordinated -OH and pyridyl groups in interlayer channels. Specifically, we show that the compound 1 can work as highly sensitive sensor to $\mathrm{Fe}^{3+}$ by luminescent quenching. Besides, the corresponding dynamic and static quenching constants are calculated, achieving the quantification evaluation of the quenching process.

\section{Experimental section}

\subsection{Materials and general methods}

All reagents and solvents were commercially available and were used without further purification. Infrared spectra were obtained in $\mathrm{KBr}$ discs on a Nicolet Avatar 360 FTIR spectrometer in the $400-4000 \mathrm{~cm}^{-1}$ region. Photoluminescence analyses were performed on an Edinburgh FLS55 luminescence spectrometer. Elemental analyses (C, H and N) were performed with a Perkin Elmer 2400C Elemental Analyzer. Thermalgravimetric analyses (TGA) were carried out in nitrogen stream using a Netzsch TG209F3 equipment at a heating rate of $5^{\circ} \mathrm{C} / \mathrm{min}$. Powder X-ray diffraction (PXRD) data were recorded on a Bruker D8 ADVANCE X-ray powder diffractometer $(\mathrm{Cu} \mathrm{K \alpha}, 1.5418 \AA)$. Electron paramagnetic resonance (EPR) spectra were recorded with a Varian E-line Century Series epr spectrometer equipped with a dual cavity and operating at X-band of $100 \mathrm{kHz}$ modulation frequency. An Axis ultra spectrometer was selected to measure X-ray photoelectron spectroscopy (XPS).

\subsection{Synthesis of $\left\{[\mathrm{Zn}(\text { bpyp })(L-O H)] \cdot D M F \cdot 2 \mathrm{H}_{2} \mathrm{O}\right\}_{n}$ (1)}

A mixture of bpyp (23.3 mg, $0.10 \mathrm{mmol}), \mathrm{L}-\mathrm{OH}(18.8 \mathrm{mg}, 0.10 \mathrm{mmol})$ and $\mathrm{Zn}\left(\mathrm{CH}_{3} \mathrm{COOH}\right)_{2} \cdot 2 \mathrm{H}_{2} \mathrm{O}(22.2 \mathrm{mg}, 0.10 \mathrm{mmol})$ was dissolved in DMF (2 mL) in a screw-capped vial. After one drop of $\mathrm{HNO}_{3}\left(62 \%\right.$, aq.) and two drops of $\mathrm{H}_{2} \mathrm{O}$ were added to the mixture, the vial was capped and placed in an oven at $105{ }^{\circ} \mathrm{C}$ for $96 \mathrm{~h}$. 
The resulting single crystals were washed with DMF and dried in air to give 1. Yield: 35\%. Elemental analysis calcd (\%) for $\mathrm{C}_{26} \mathrm{H}_{26} \mathrm{ZnN}_{4} \mathrm{O}_{8}$ : C, 53.12; H, 4.46; N, 9.53. Found: C, 54.14; H, 4.87; N, 10.02\%. IR (KBr, cm ${ }^{-1}$; see Fig S1): 3738(m), 3439(s), 3030(w), 2776(m), 2457(w), 1549(m), 1377(s), 1016(m), 888(m), 815(m), 713(m), 561(m).

\subsection{X-ray data collection and structure determination}

The diffraction data were collected at 295(2) for 1, with a Bruker-AXS SMART CCD area detector diffractometer using $\omega$ rotation scans with a scan width of 0.3 and Mo $\mathrm{K} \alpha$ radiation $(\lambda=0.71073 \AA)$. Absorption corrections were carried out utilizing SADABS routine [25]. The structure was solved by direct methods and refined using the SHELXTL 97 software [26]. Atoms were located from iterative examination of difference Fmaps following least squares refinements of the earlier models. All the atoms except hydrogen atoms, which were fixed at calculated positions and refined by using a riding mode, were refined anisotropically until full convergence was achieved. It was necessary to constrain or restrain a number of bond lengths and angles in the structure in order get a stable refinement and chemically reasonable model. For $\mathbf{1}$, the microporous framework was occupied by extremely electron density, which could be assigned to be free solvent molecules. Because these guest solvents in the crystal is highly disordered and impossible to refine using conventional discrete-atom models, the SQUEEZE subroutine of the PLATON software suite was applied to remove the scattering from the highly disordered solvent molecules [27], and sets of solvent-free diffraction intensities were produced. The free solvent molecules for the $\mathbf{1}$ were determined by combining single crystal structures, element a microanalysis and TGA date. The crystallographic data and selected bond lengths and angles for $\mathbf{1}$ are listed in Table S1 and Table S2. Crystallographic data for the structural analysis has been deposited with the Cambridge Crystallographic Data Center. 


\section{Results and discussion}

\subsection{The structural features}

Single crystal X-ray diffraction analysis reveals that polymer $\mathbf{1}$ possesses a network structure and crystallizes in monoclinic space group P21/c. The structure of $\mathbf{1}$ contains only a distorted tetrahedral Zn(II) atom, which is coordinated to two bpyp and two L-OH ligands with the average $\mathrm{Zn}-\mathrm{O}$ and $\mathrm{Zn}-\mathrm{N}$ bond distances of 1.917 and $2.066 \AA$, respectively. The view of the coordination geometry is shown in Fig. 1a. In 1, the bpyp ligands alternately bridge Zn(II) atoms to form infinite [Zn(bpyp) $]_{n}$ chains. The adjacent chains are further connected by L-OH to construct wavelike $2 \mathrm{D}(4,4)$ grids layer. It is particularly worth mentioning that the polymeric sheets are further interlinked by hydrogen-bonding interactions (Fig. S2) $(\mathrm{O}-\mathrm{H} \cdots \mathrm{O}=2.659 \AA$ ) to form an overall three-dimensional channels structure, large cavities are decorated by uncoordinated pyridyl and $-\mathrm{OH}$, as illustrated in Fig. 1b. The PLATON calculations suggest that the solvent-accessible volume and porosity are $748.5 \AA^{3}$ and $28.7 \%$ void space after excluding DMF and $\mathrm{H}_{2} \mathrm{O}$.

\section{Fig. 1a}

Fig. 1b

\subsection{Thermal analysis}

In order to identify the thermal stability of complex $\mathbf{1}$, the thermogravimetric analyses (TGA) has been studied (Fig. S3). The first weight loss of $19.82 \%$ from 140 to $180{ }^{\circ} \mathrm{C}$ corresponds to the loss of all the DMF and $\mathrm{H}_{2} \mathrm{O}$ molecules (calcd $18.54 \%$ ). From 180 to $340{ }^{\circ} \mathrm{C}$, the TGA curve of 1 passes through a flat area, and then begin to collapse with the loss of other organic molecules.

\subsection{Selective Detection of $\mathrm{Fe}^{3+}$ ion}

Since polymer $\mathbf{1}$ is constructed with a $\mathrm{d}^{10}$ electron configuration $\mathrm{Zn}^{2+}$ ion and two fluorescent rigid ligands (bpyp and L-OH, Fig. S4), they are highly possible to show photoactivity. Besides, the above structure analyses show that polymer $\mathbf{1}$ possess high 
thermal stability and Lewis basic sites such as exposed pyridine $\mathrm{N}$ atom, - $\mathrm{OH}$, and can largely improve their ability to recognize and sense ionic species.

The luminescent responses of $\mathbf{1}$ (5mg) to various metal ions have been investigated by dispersing in 1@DMF solutions of different nitrate (3 mL, $0.1 \mathrm{~mol} / \mathrm{L}$; Group A: $\mathrm{KNO}_{3}, \mathrm{Ca}\left(\mathrm{NO}_{3}\right)_{2}, \mathrm{~Pb}\left(\mathrm{NO}_{3}\right)_{2}, \mathrm{Cd}\left(\mathrm{NO}_{3}\right)_{2}, \mathrm{Zn}\left(\mathrm{NO}_{3}\right)_{2}$; Group B: $\mathrm{Mn}\left(\mathrm{NO}_{3}\right)_{2}, \mathrm{Co}\left(\mathrm{NO}_{3}\right)_{2}$, $\mathrm{Ni}\left(\mathrm{NO}_{3}\right)_{2}, \mathrm{Cu}\left(\mathrm{NO}_{3}\right)_{2}, \mathrm{Fe}\left(\mathrm{NO}_{3}\right)_{3}$. As shown in Fig. 2a and Fig. S5, the luminescent intensities are greatly determined by the metal ions. The addition of metal ions from Group A can hardly cause decrease in intensity, while ions from Group B could induce luminescence quenching at certain degrees, especially for $\mathrm{Fe}^{3+}$, which can bring complete quenching to the system. This result demonstrates that the compound $\mathbf{1}$ can be highly effective and selective luminescent sensing for $\mathrm{Fe}^{3+}$ ion. The decreases of intensity caused by $\mathrm{Fe}^{3+}$ ions induce ligand to metal charge-transfer (LMCT) and provide a non-radiative pathway for the excitation energy [28-30]. As confirmed by the powder X-ray diffraction (PXRD) patterns (Fig. 2b), the crystal structures of $\mathbf{1}$ immersed in metal ions solutions remain unchanged. The UV-Vis absorption spectra for $\mathrm{Fe}^{3+}$ solutions have been recorded (Fig. S6). The absorption spectrum of $\mathrm{Fe}^{3+}$ solution has a large overlap with the excitation spectrum of $\mathbf{1}$, indicating the existence of energy transfer. Therefore, the quenching caused by $\mathrm{Fe}^{3+}$ is the combination of the photo induced electron transfer and energy transfer [31, 32].

Fig. 2a

Fig. 2b

Fig. 2c

3.4 Quenching modes: dynamic and static quenching processes

X-ray photoelectron spectroscopy (XPS), Electron paramagnetic resonance (EPR), titration experiments, concentration-dependent lifetime measurements and 
time-dependent intensity experiments have been conducted to explore whether the quenching process is dynamic or static.

The X-ray photoelectron spectroscopy (XPS) experiment on $\mathbf{F e}^{3+} @ 1$ showed that the typical energy of $\mathrm{Fe}^{3+}$ (712.36, 725.81), demonstrates the interaction between $\mathrm{Fe}^{3+}$ and framework (Fig. 3a). Besides, Electron paramagnetic resonance (EPR) spectra are performed on $\mathrm{Fe}^{3+} @ 1$ and 2.109 is a typical EPR signal corresponding to the paramagnetic $\mathrm{Fe}^{3+}$ ions (Fig. $3 \mathbf{b}$ ).

\section{Fig. 3a}

Fig. 3b

In titration experiment, the emission responses were adjusted by the gradual addition of Fe( $\left.\mathrm{NO}_{3}\right)_{3} @ \mathrm{DMF}$ solution (0.1 mol/L) into the suspension of 1@DMF. As demonstrated in Fig. 2c, the increased amount of $\mathrm{Fe}^{3+}$ resulted in a gradual decrease of luminescence intensity at $375 \mathrm{~nm}$, and the intensity reduced to $50 \%$ at a concentration of $10 \mathrm{ppm}$ for $\mathrm{Fe}\left(\mathrm{NO}_{3}\right)_{3}$, which means high sensitivity to $\mathrm{Fe}^{3+}$. The luminescence quenching efficiency of $\mathbf{1}$ is analyzed by the Stern-Volmer (SV) equation, $\left(\mathrm{I}_{0} / \mathrm{I}\right)=\mathrm{K}_{\mathrm{SV}} *_{\mathrm{c}}+1$ (I), was measured to calculate the corresponding quenching coefficient ( $I_{0}$ is the initial intensity, $I$ is the intensity at the corresponding concentration of $c$, and the $K_{\mathrm{SV}}$ is the quenching constant $\left.\left(\mathrm{M}^{-1}\right)\right)$. Notably, the $\mathrm{S}-\mathrm{V}$ curves deviate from the straight line (Fig. 4a), and this phenomenon suggests that more than one quenching mechanisms appear in the process, including dynamic quenching and static quenching [33].

Fig. 4a

Fig. 4b

Fig. 4c

Generally speaking, in static quenching process, a non-emissive ground-state 
complex has been formed by the sensor and the quencher; while in the dynamic process, electron transfer can be obtained by the collision of the sensor and the analytes [34]. When dynamic and static quenching are both incorporated in the quenching process, the overall S-V curve could be rewritten as $\left(I_{0} / I\right)=\left(K_{c} * c+1\right) *$ $\left(K_{s} *_{c}+1\right)$, where $K_{c}$ and $K_{s}$ represent the dynamic constant and the static quenching constant, respectively. However, whether the quenching is dominated by dynamic or static process cannot be estimated just based on a single S-V function. Fortunately, the two distinct processes can be distinguished by the luminescence lifetime changes at different concentration. Dynamic quenching can cause decrease of lifetime by collisions to luminescent coordination polymers (LCPs) at excited state, but static quenching cannot [35-38].

Hence, luminescence lifetime measurement is employed to calculate the effect of dynamic quenching by Stern-Volmer equation of $\tau_{0} / \tau=1+\mathrm{Kc} * \mathrm{c}\left(\tau_{0}=\right.$ the original lifetime of $\mathbf{1}, \tau=$ the lifetime at the analyte concentration of c). As a result, concentration-dependent lifetime experiment has been conducted and the decrease in lifetime confirm the existence of dynamic quenching by gradual addition of Fe( $\left.\mathrm{NO}_{3}\right)_{3} @ \mathrm{DMF}$ solution (0.05 mol/L) into the suspension of 1@DMF. (Fig. S7). The corresponding S-V plots and the dynamic quenching constant are calculated as $3660 \mathrm{M}^{-1}$ for 1 , as shown in Fig. $4 \mathbf{b}$.

When the concentration is very low, $\mathrm{K}_{\mathrm{c}} * \mathrm{~K}_{\mathrm{s}} * \mathrm{c}^{2}$ could be neglected, the overall S-V equation could be simplified as $\left(I_{0} / I\right)=\left(K_{c}+K_{s}\right) * c+1$, and yield a linear plot, by which $K_{s}$ can be obtained. The overall S-V equations are refitted with the dynamic constant $K_{c}$ calculated from the lifetime experiments and the data at low concentration. As shown in Fig. 4c, the static constant is calculated as $64000 \mathrm{M}^{-1}$ for $\mathbf{1}$. So, the overall $K_{\mathrm{sv}}$ constants are obtained (Table 1), calculated from the sum of the corresponding $K_{c}$ and $K_{s}$. It is clear that static quenching dominates the process of $\mathbf{1}$.

As mentioned above, static quenching is related to the static interaction between the sensor and the analytes, while dynamic quenching results from the collision. Structure analyses show that there exist exposed pyridine $\mathrm{N}$ atoms and $-\mathrm{OH}$ groups in polymer 
1, which may easily create static quenching by the interaction between active atoms and $\mathrm{Fe}^{3+}$.

\section{Table 1}

Fig. 5

Moreover, time-dependent experiment also gives side proof for the quenching processes. Fig. 5 demonstrates that the luminescence intensity of $\mathbf{1}$ decreases on the addition of $\mathrm{Fe}\left(\mathrm{NO}_{3}\right)_{3}(0.1 \mathrm{~mol} / \mathrm{L}, 5 \mathrm{~d})$ along with time following the first-order exponential decay formula of $I=35.25 * \exp (-t / 26.25)+8.33$. As the prerequisite of effective static interaction, the collision should be the faster process than static interaction and the later one is believed to function as a slower continuous process, causing intensity declining along with time, as in the case described for $\mathbf{1}$. The time-dependent experiment could give indication that the static quenching is much more effective to $\mathbf{1}$ with decoration of functional groups.

\section{Conclusions}

In this work, a novel porous luminescent coordination polymer, $\left\{[\mathrm{Zn}(\mathrm{bpyp})(\mathrm{L}-\mathrm{OH})] \cdot \mathrm{DMF} \cdot 2 \mathrm{H}_{2} \mathrm{O}\right\}_{\mathrm{n}}(\mathbf{1})$, containing uncoordinated $-\mathrm{OH}$ and pyridyl groups in interlayer channels was successfully synthesized and characterized. Photoluminescence studies show that compound $\mathbf{1}$ can exhibit significant luminescent sensitivity to $\mathrm{Fe}^{3+}$, which make its good candidate as luminescent sensor. Importantly, 1 shows distinct behaviors that static quenching dominates the quenching process. Structure analyses show that there exist exposed pyridine $\mathrm{N}$ atoms and - $\mathrm{OH}$ groups in compound 1, which may easily create static quenching by the interaction between active atoms and $\mathrm{Fe}^{3+}$ through interactions. Besides, the corresponding dynamic and static quenching constants are calculated, achieving the quantification evaluation of the quenching process. There are two active sites in $\mathbf{1}$, so the quenching effect is better that other compounds [39, 40]. This work not only achieves the quantitative evaluation of the 
luminescence quenching but also provides certain insights into the quenching process, and the possible mechanisms explored in this work may inspire future research and design of target LCPs with specific functions.

\section{Acknowledgements}

We are grateful for financial support from the NSF of China (Grants 21531007, 21401143, 21401121, 21371142, 21201139); The NSF of Anhui, China (Grants 1508085QB35); Natural Science Research Project of Anhui Colleges and Universities (KJ2015A286); The research projects by Northwest University (2015120); The Science and Technology Project of Anhui Province (Grants 1206c0805031 and 1406c085021).

\section{References}

[1] D.E. Williams, J.A. Rietman, J.M. Maier, R. Tan, A.B. Greytak, M.D. Smith, J.A. Krause, N.B. Shustova, J. Am. Chem. Soc. 136 (2014) 11886-11889.

[2] W.-G. Lu, Z.-W. Wei, Z.-Y. Gu, T.-F. Liu, J. Park, J. Tian, M.W. Zhang, Q. Zhang, T. Gentle, M. Bosch, H.C. Zhou, Chem. Soc. Rev. 43 (2014) 5561-5593.

[3] L.-J. Li, S.-F. Tang, C. Wang, X.-X. Lv, M. Jiang, H.-Z. Wu, X.-B. Zhao, Chem. Commun. 50 (2014) 2304-2307.

[4] S.-L. Qiu, M. Xue, G.-S. Zhu, Chem. Soc. Rev. 43 (2014) 6116-6140.

[5] X.-Z. Song, S.-Y. Song, S.-N. Zhao, Z.-M. Hao, M. Zhu, X. Meng, L.-L. Wu, H.-J. Zhang, Adv. Funct. Mater. 24 (2014) 4034-4041.

[6] J.-C. Jin, W.-Q. Tong, A.-Y. Fu, C.-G. Xie, W.-G. Chang, J. Wu, G.-N. Xu, Y.-N. Zhang, J. Li , Y. Li , P.-Q. Yang, J. Solid State Chem. 225 (2015) 216-221.

[7] Y. -Cui, G. Qian, B. Chen, Chem. Rev. 112 (2012) 1126-1162.

[8] J.-C. Jin, Y.-N. Zhang, Y.-Y. Wang, Z. Dong, Q.-Z. Shi, Chem. Asian J. 5 (2010) 1611-1619.

[9] J.J. Perry IV, J. A. Perman, M. J. Zaworotko, Chem. Soc. Rev. 38 (2009) 1400-1417. 
[10] M. O’Keeffe, O. M. Yaghi, Chem. Rev. 112 (2012) 675-702.

[11] D.-S. Li, Y.-P. Wu, J. Zhao, J. Zhang, J.-Y. Lu, Coord. Chem. Rev. 261 (2014) $1-27$.

[12] L.-Y. Pang, G.-P. Yang, J.-C. Jin, M. Kang, A.-Y. Fu, Y. -Y. Wang, Q.-Z. Shi, Cryst. Growth Des. 14 (2014) 2954-2961.

[13] D.-S. Li, J. Zhao, Y.-P. Wu, B. Liu, L. Bai, K. Zou, M. Du, Inorg. Chem. 52 (2013) 8091-8098.

[14] H.-B. Xu, S.-H Zhou, L.-L. Xiao, H.-H. Wang, S. Li, Q. Yuan, J. Mater. Chem. C. 3 (2015) 291-297.

[15] K. Jayaramulu, R. P. Narayanan, S. J. George, T. K. Maji, Inorg. Chem. 51 (2012) 10089-10091.

[16] X.-H. Zhou, L. Li, H.-H. Li, A. Li, T. Yang, W. Huang, Dalton Trans. 42 (2013) 12403-12409.

[17] H.-T. Zhang, J.-W. Zhang, G. Huang, Z.-Y. Du, H.-L. Jiang, Chem. Commun. 50 (2014) 12069-12072

[18] Y.-J. Cui, W.-F. Zou, R.-J. Song, J.-C. Yu, W.-Q. Zhang, Y.Yang, G.D. Qian, Chem. Commun. 50 (2014) 719-721.

[19] A.B. Bon, A.M. Costero, S. Gil, Chem. Commun. 48 (2012) 3000-3002.

[20] E. Gaggelli, H. Kozlowski, D. Valensin, G. Valensin, Chem. Rev. 106 (2006) 1995-2044.

[21] S. Pramanik, Z.-C. Hu, X. Zhang, C. Zheng, S. Kelly, J. Li, Chem.Eur. J. 15 (2013) 15964-15971.

[22] K.P. Carter, A.M. Young, A.E. Palmer, Chem. Rev. 114 (2014) 4564-4601.

[23] S.K. Sahoo, D. Sharma, R.K. Bera, G. Crisponic, J.F. Callan, Chem. Soc. Rev. 41 (2012) 7195-7221.

[24] L.M. Hyman, K.J. Franz, Coord. Chem. Rev. 256 (2012) 2333-2356.

[25] Bruker. SADABS, SMART, SAINT. Bruker AXS Inc., Madison, Wisconson, USA, 2002.

[26] G.M. Sheldrick, University of Göttingen, Germany, 1997. 
[27] A.L. Spek, Acta Crystallogr., Sect. A. 46 (1990) C34.

[28] M.D. Allendorf, C.A. Bauer, R.K. Bhakta, R.J.T. Houk, Chem. Soc. Rev. 38 (2009) 1330-1352.

[29] K. Jayaramulu, R.P. Narayanan, S.J. George, T.K. Maji, Inorg. Chem. 51 (2012) 10089-10091.

[30] J.-X. Ma, X.-F. Huang, X.-Q. Song, W.-S. Liu, Chem. Eur. J. 19 (2013) 3590-3595.

[31] S.S. Nagarkar, B. Joarder, A.K. Chaudhari, S. Mukherjee, S.K. Ghosh, Angew. Chem. Int. Ed. 52 (2013) 2881-2885.

[32] S. Pramanik, C. Zheng, X. Zhang, T.J. Emge, J. Li, J. Am. Chem. Soc. 133 (2011) 4153-4155.

[33] B. Gole, A.K. Bar, P.S. Mukherjee, Chem. Eur. J. 20 (2014) 2276-2291.

[34] L.K. Fraiji, D.M. Hayes, T.C. Werner, Journal of Chemical Education. 69 (1992) 424-428.

[35] A.-J. Lan, K.-H. Li, H.-H. Wu, D.H. Olson, T.J. Emge, W. Ki, M.C. Hong, J. Li, Angew. Chem., Int. Ed. 48 (2009) 2334-2338.

[36] S.Pramanik, C. Zheng, X. Zhang, T.J. Emge, J. Li, J. Am. Chem. Soc. 133 (2011) 4153-4155.

[37] S.-Q. Zhang, L. Han, L.-N. Li, J. Cheng, D.-Q. Yuan, J.-H. Luo, Cryst. Growth Des.13 (2013) 5466-5472.

[38] B. Gole, A.K. Bar, P.S. Mukherjee, Chem. Commun. 47 (2011) 12137-12139.

[39] L.-Y. Pang, G.-P. Yang, J.-C. Jin, M. Kang, A.-Y. Fu, Y.-Y. Wang, Q.-Z. Shi, Cryst. Growth Des. 14 (2014) 2954-2961.

[40] Y.-T. Liang, G.-P. Yang B. Liu, Y.-T. Yan, Z.-P. Xi, Y.-Y. Wang, Dalton Trans. 44 (2015) 13325-13330. 
Fig. 1 (a) The coordination environment of Zn in 1 (Symmetry codes: A x, y, 0.5-z); (b) $3 \mathrm{D}$ channels structure with uncoordinated pyridyl and $-\mathrm{OH}$.

Fig. 2 (a) Comparison of the relative luminescence intensities of various 1@M(NO $\left.\mathrm{NO}_{3}\right)_{\mathrm{x}} @ \mathrm{DMF}$ suspensions; (b) PXRD patterns of $\mathrm{M}\left(\mathrm{NO}_{3}\right)_{\mathrm{x}}$ immersion; (c) Emission spectra of $\mathbf{1}$ dispersed in DMF with the titration of $\mathrm{Fe}\left(\mathrm{NO}_{3}\right)_{3}$.

Fig. 3 (a) The X-ray photoelectron spectroscopy (XPS) experiment on $\mathbf{F e}^{\mathbf{3}^{+} @ \mathbf{1}}$ showed that typical energy of $\mathrm{Fe}^{3+}$; (b) The typical EPR signal corresponding to the paramagnetic $\mathrm{Fe}^{3+}$ ions.

Fig. 4 (a) View of the S-V curves of compound 1; (b) The dynamic quenching constant is calculated as $3600 \mathrm{M}^{-1}$ for $\mathbf{1}$; (c) The static constant is calculated as 64000 $\mathrm{M}^{-1}$ for 1 .

Fig. 5 The time-dependent intensity of $\mathbf{1}$. 


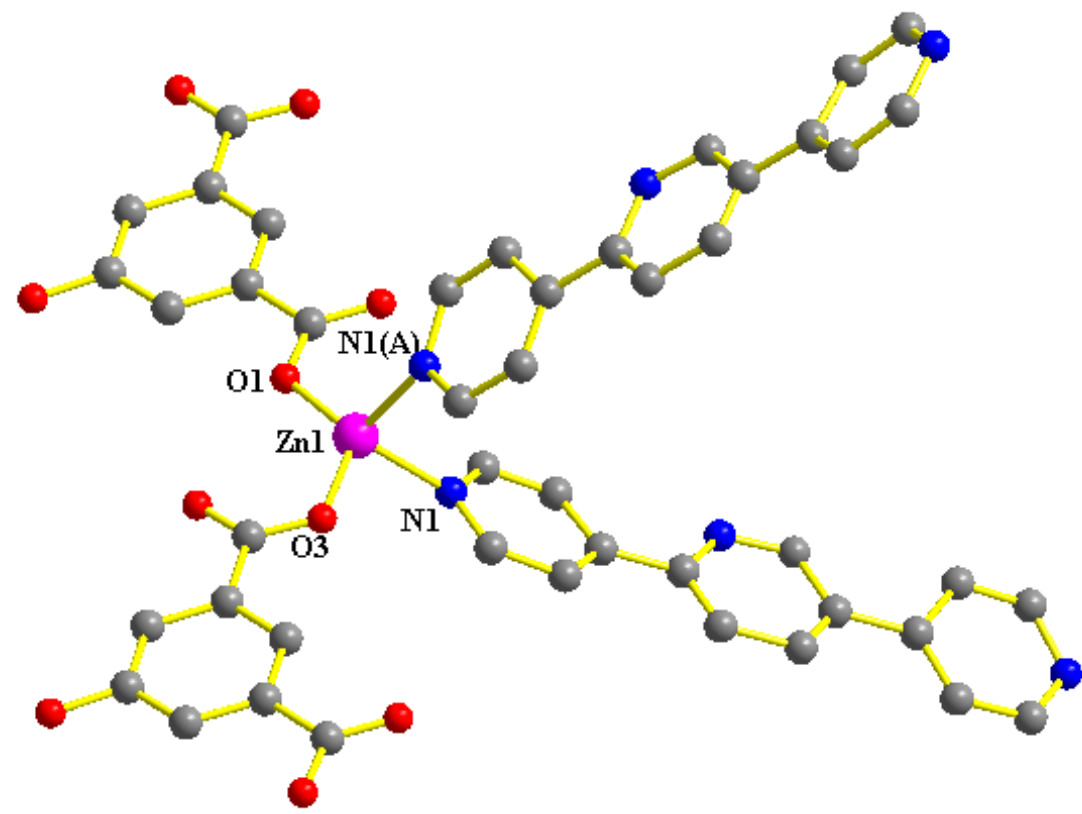

Fig. 1a

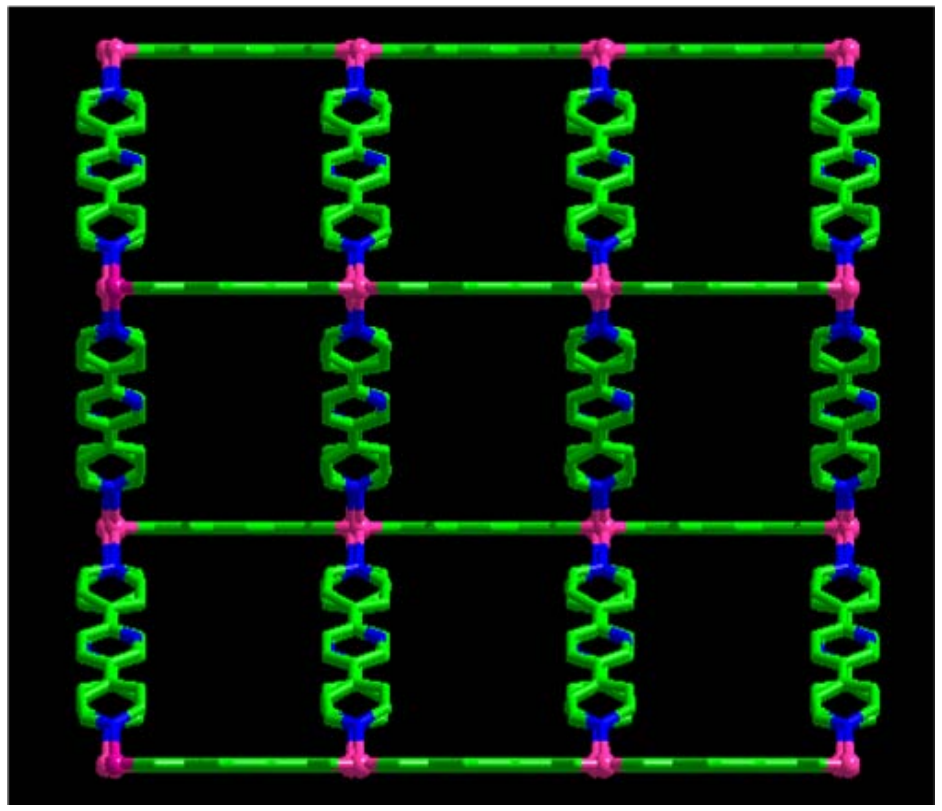

Fig. 1b 


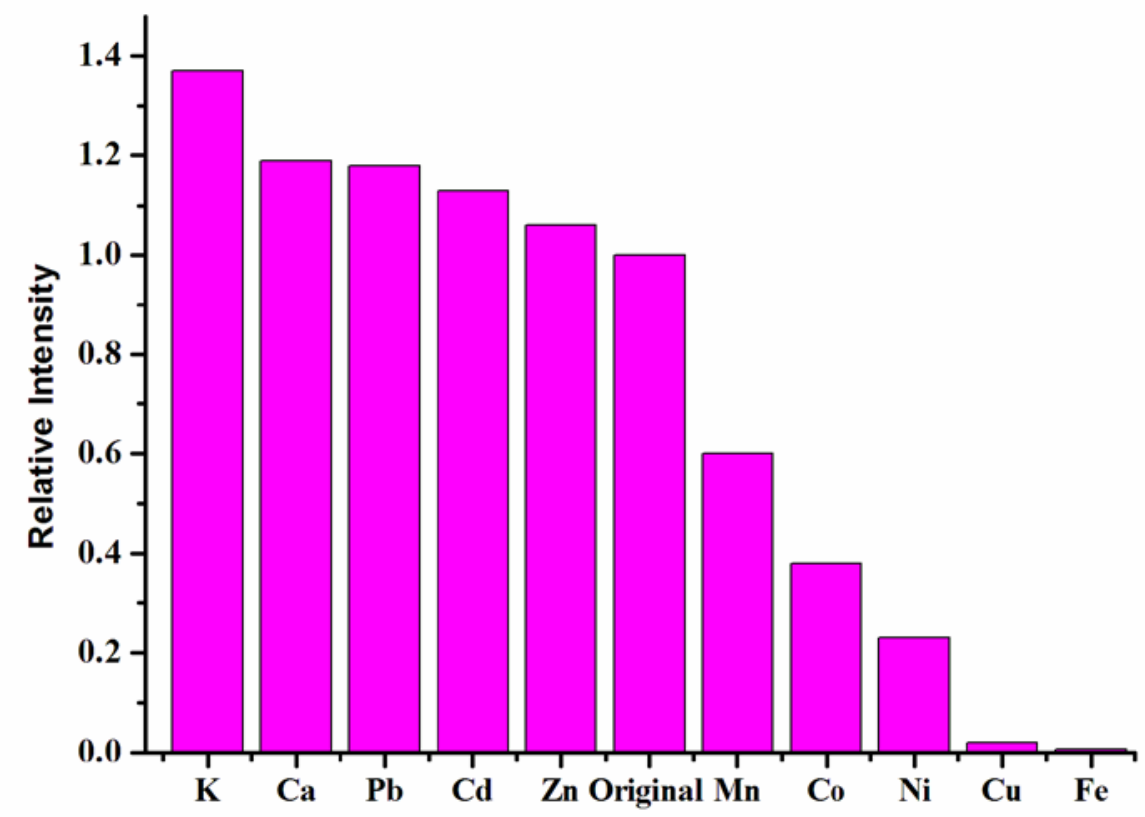

Fig. 2a

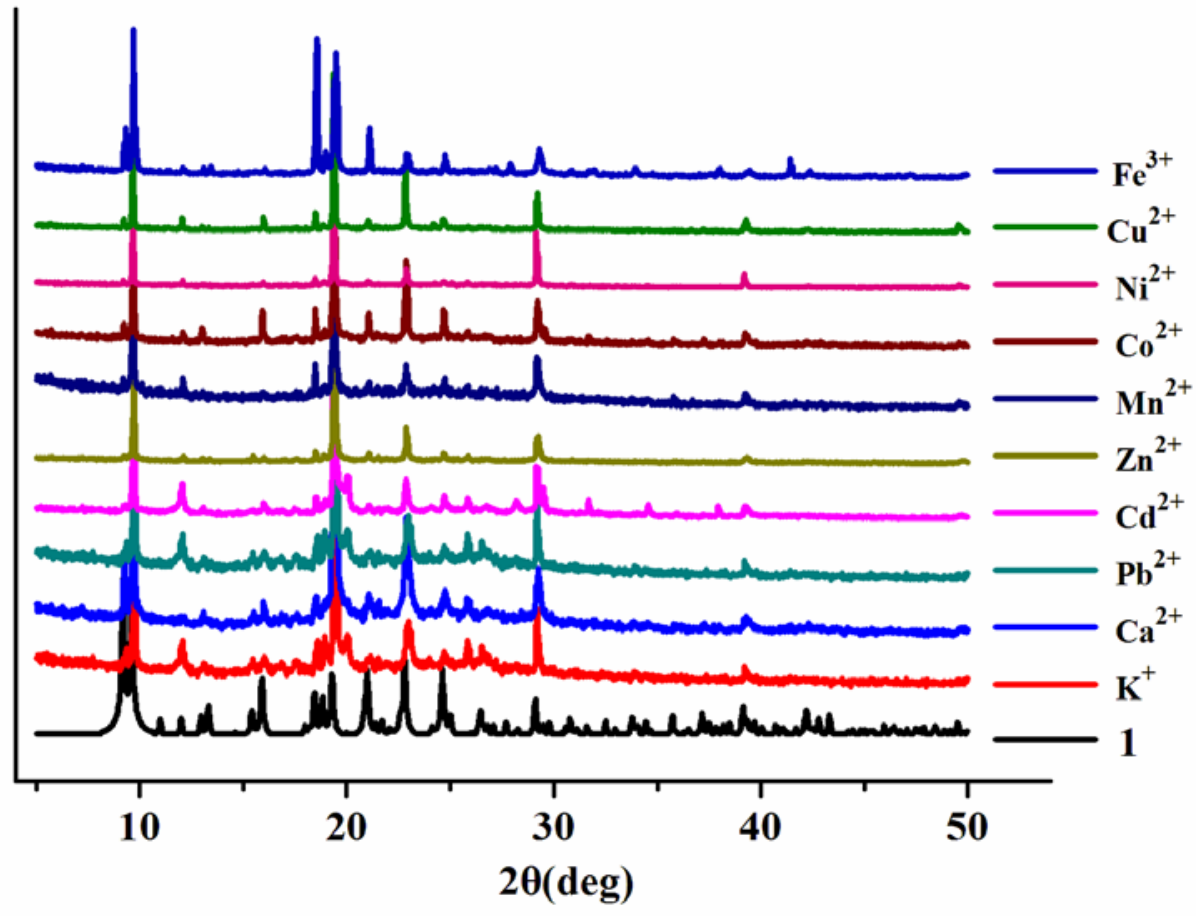

Fig. 2b 


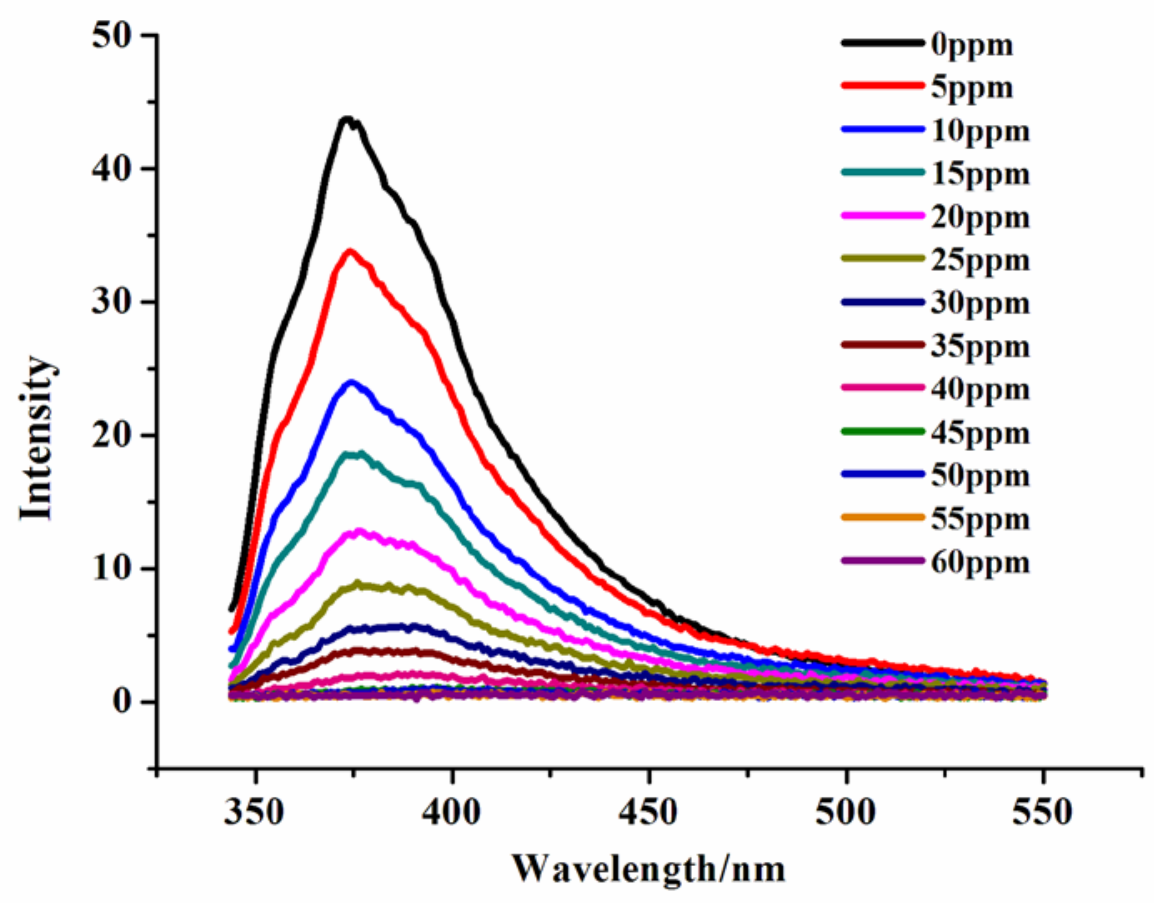

Fig. 2c

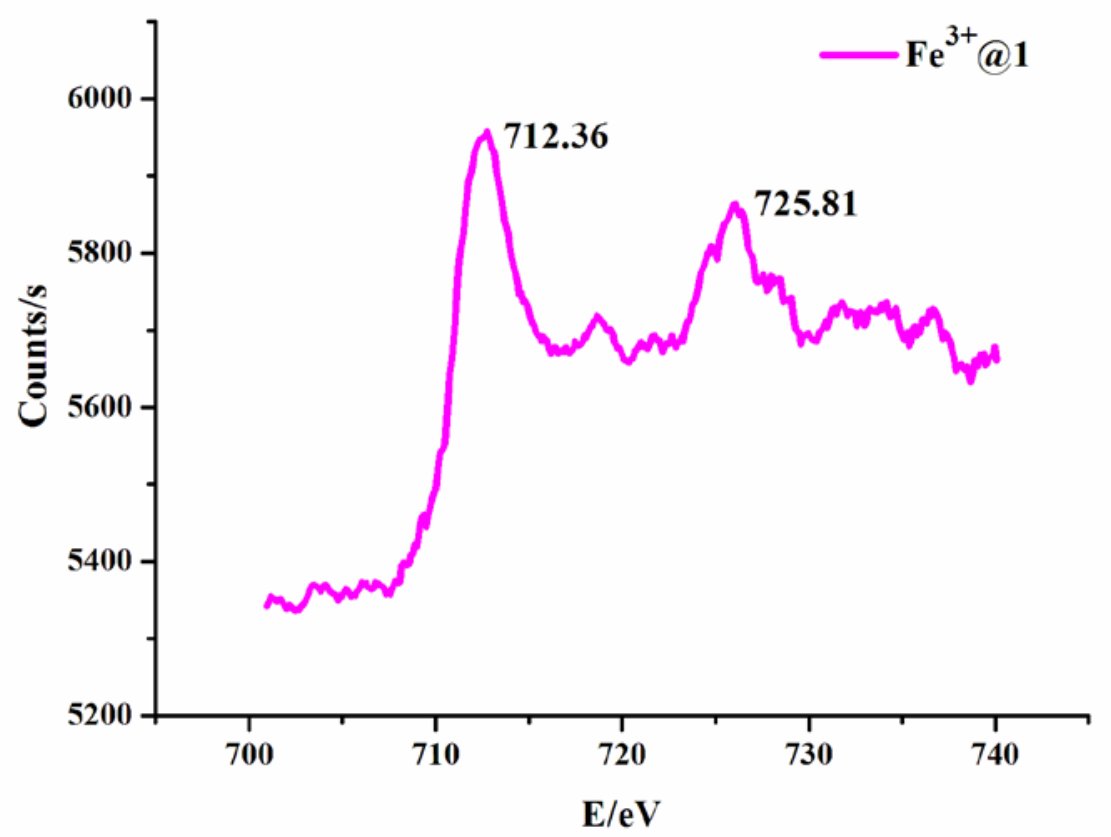

Fig. 3a 


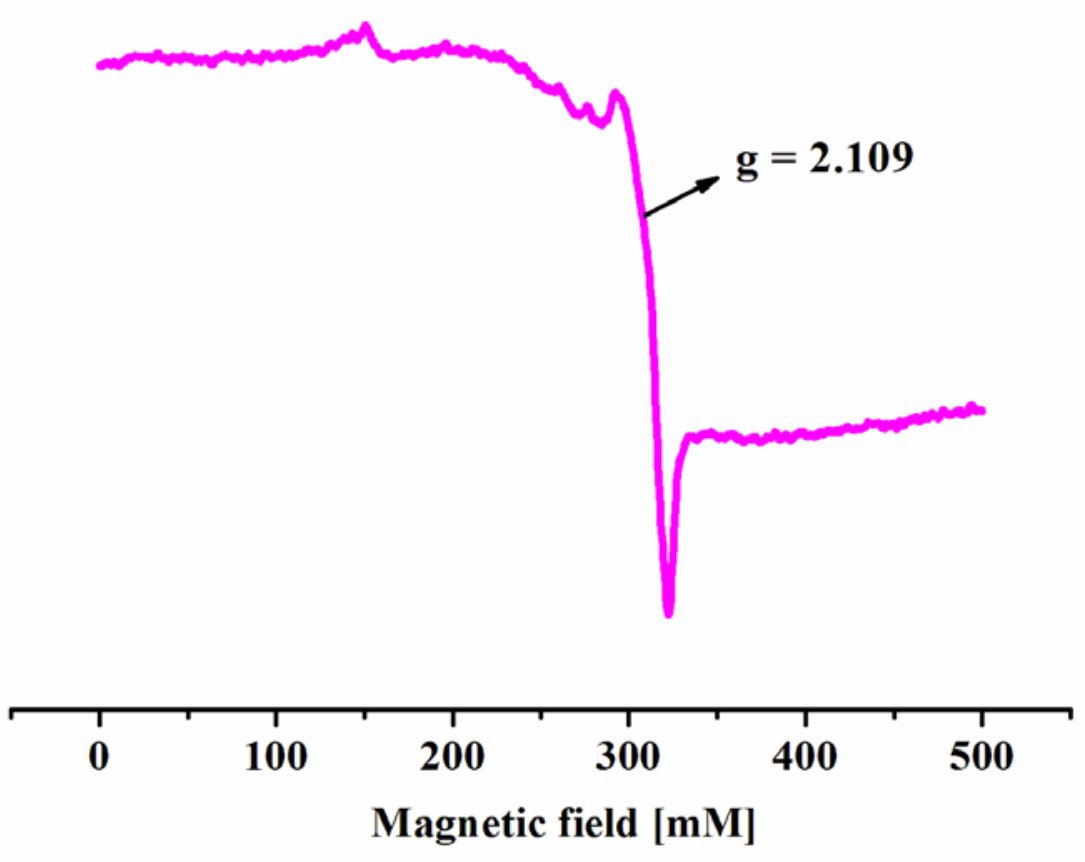

Fig. 3b

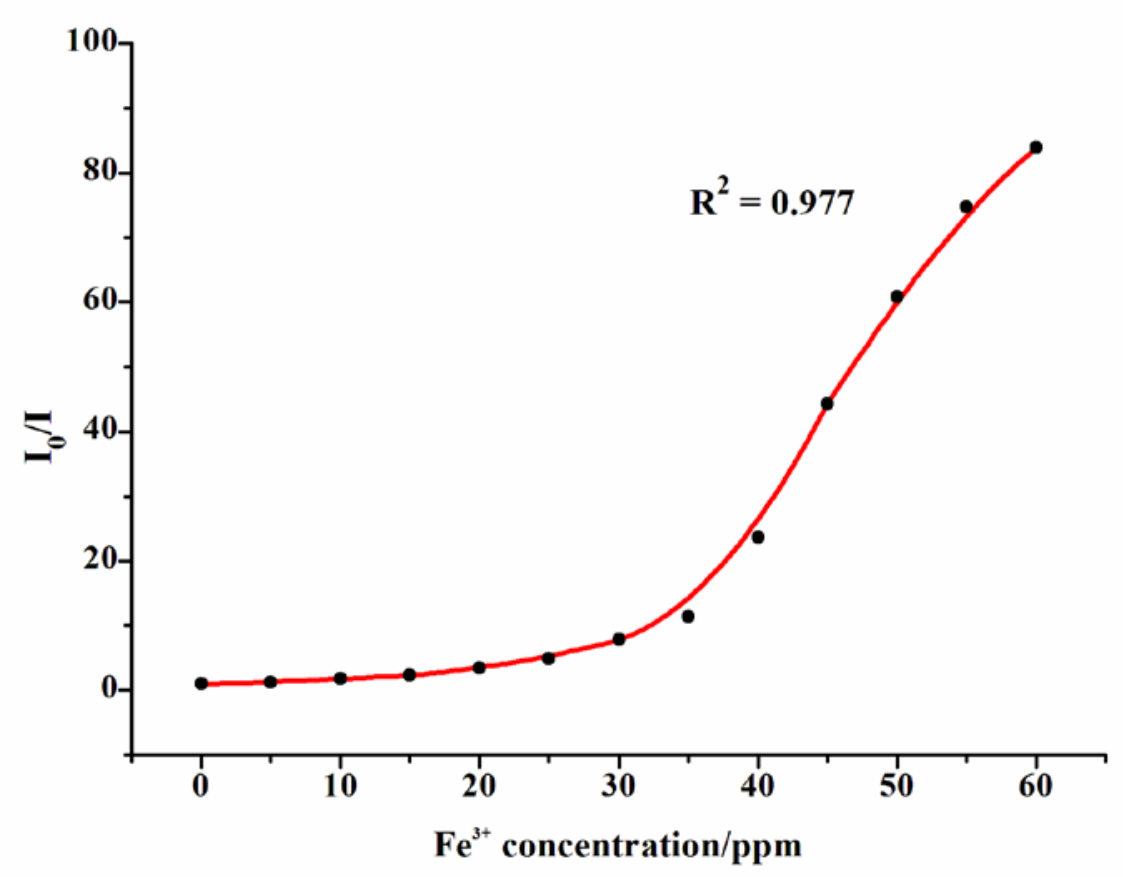

Fig. 4a 


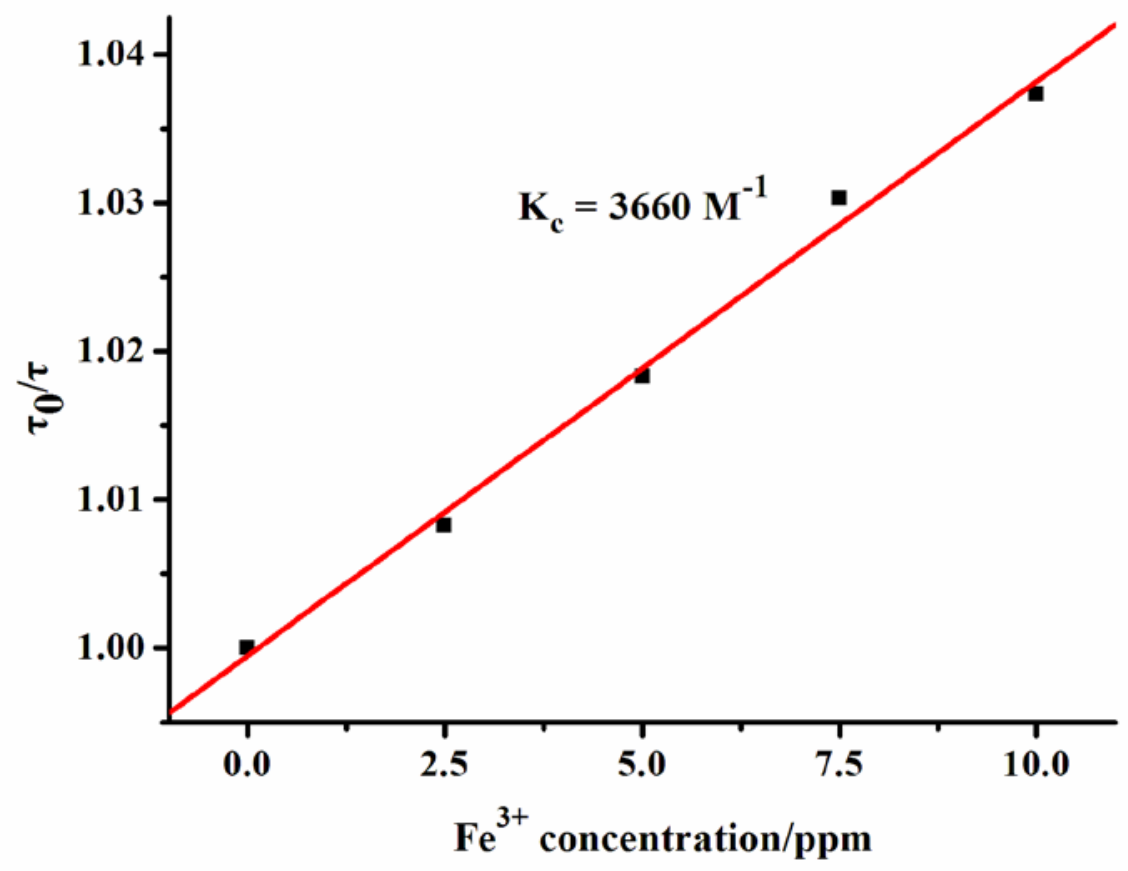

Fig. 4b

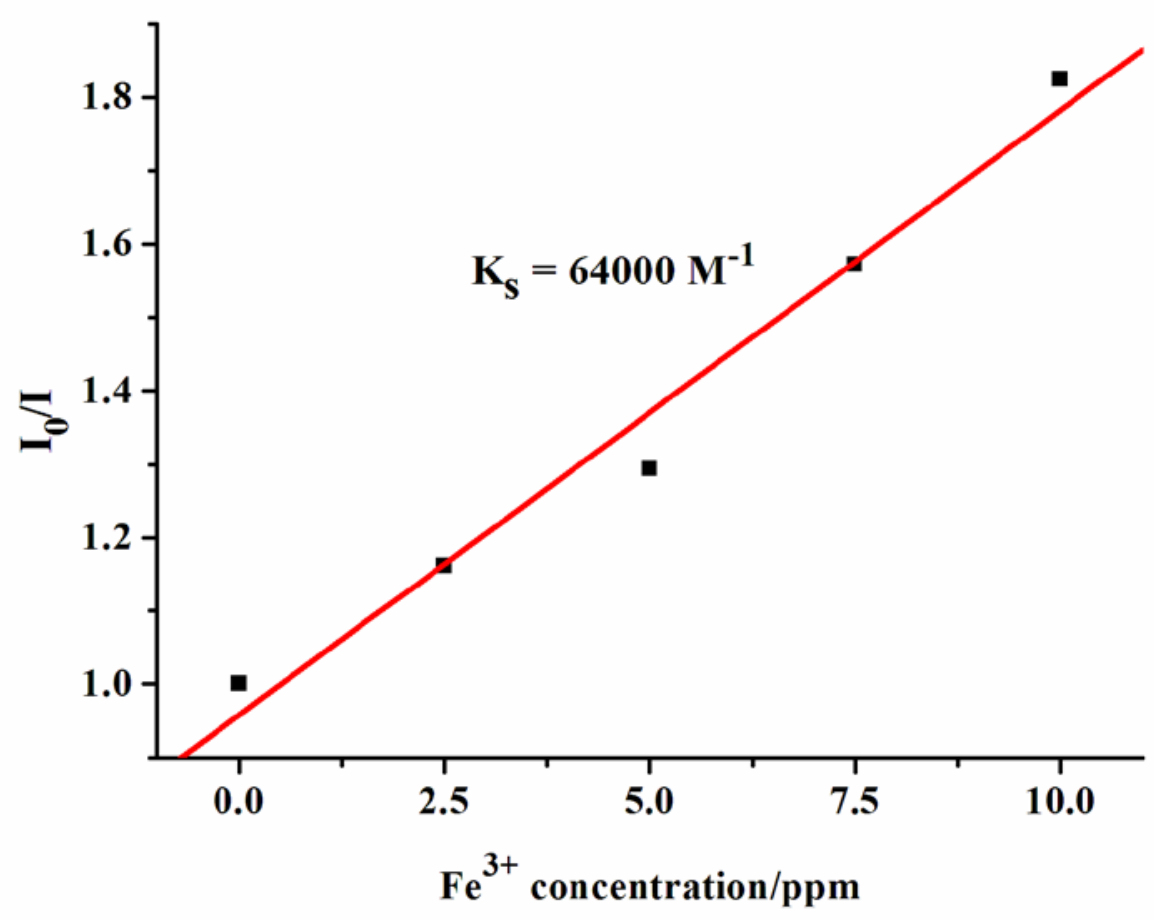

Fig. 4c 


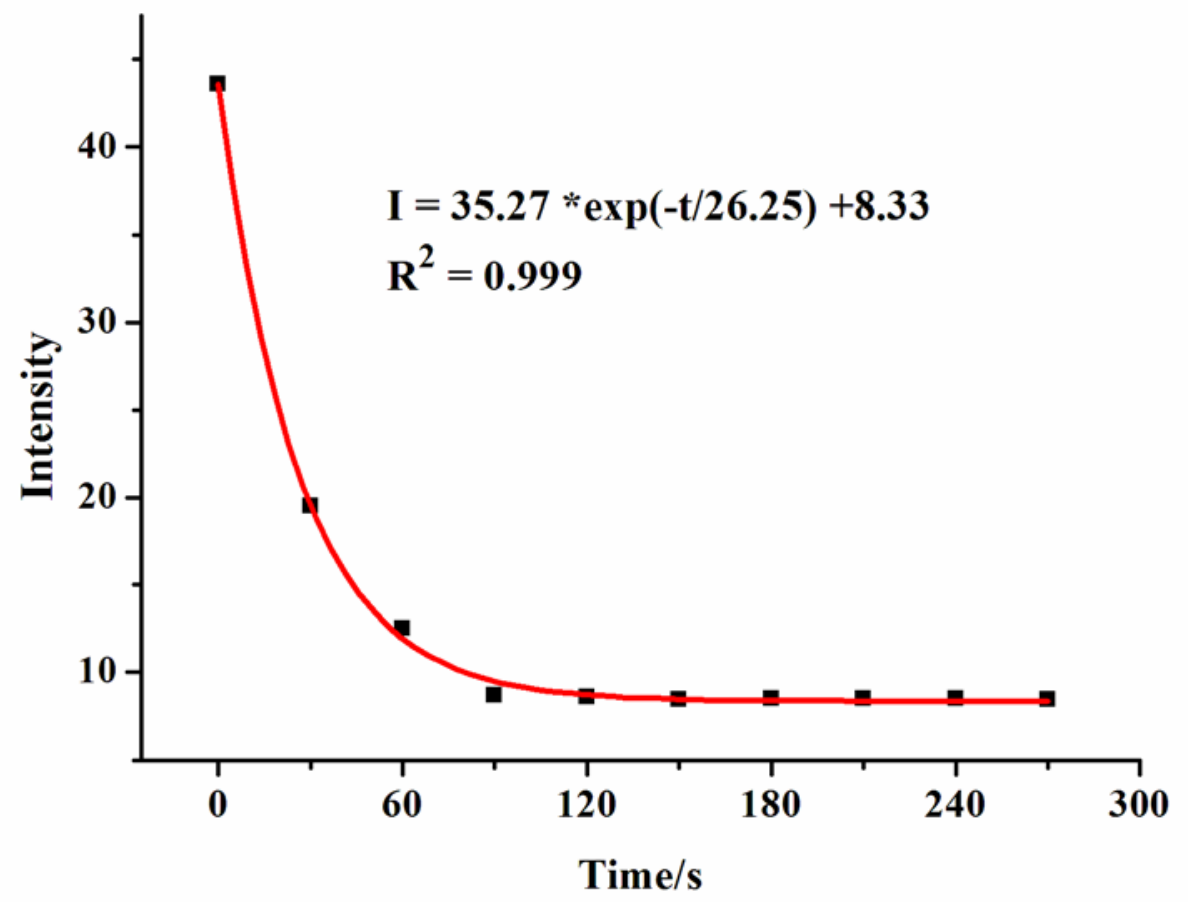

Fig. 5 